\title{
80th Anniversary of the Journal
}

DOI: $10.1134 / \mathrm{S} 1062359016010143$

This year, this journal celebrates the 80th anniversary of the start of its publication in Moscow. This date was associated with the movement of the Academy of Sciences of the Soviet Union to Moscow.

This journal began its existence in 1845 in St. Petersburg, where it was published under the name Bulletin of Fundamental Physicomathematical Sciences of the Academy of Sciences. Since then, the name has changed several times: in 1860 it was renamed the Bulletin of the Russian Imperial Academy of Sciences (series 3); in 1894, Bulletin of the Imperial Academy of Sciences (series 4); in 1917, Bulletin of the Russian Academy of Sciences; in 1936, Bulletin of the Academy of Sciences of the Union of Soviet Socialistic Republics: Biological Series; and in 1992, Bulletin of the Russian Academy of Sciences: Biological Series.

The journal was published in Russian, German, French, and English. The main rubrics included "Extract from Protocols of the Academy of Sciences," "Reports on Scientific Papers" (detailed reports on expeditions and field and laboratory research), and "Articles" (covering theoretical and experimental issues of biology). The journal was published in separate issues, which were typed and published as the material accumulated.

Before the revolution, the head of the journal was the secretary of the Academy of Sciences and the editorial board included such prominent scientists as V.I. Vernadskii, S. Ol'denburg, and A.E. Fersman. In the Soviet period, in the 1920s, the editor-in-chief was Academician A.A. Borisyak, and the editorial board included Academicians N.I. Vavilov, A.A. Rikhter, and D.S. Rozhdestvenskii. The authors of the journal included such eminent scientists as I.M. Sechenov,
K.A. Timiryazev, I.I. Mechnikov, V.A. Dogel', and V.V. Zalenskii.

After the move of the journal to Moscow in 1936, the President of the Academy of Sciences of the USSR, Academician V.L. Komarov became the editor-in-chief of the journal, and after his death the journal was headed by prominent Russian biologists Academicians L.A. Orbeli, A.I. Oparin, E.N. Mishustin, and N.G. Khrushchov.

At present, the journal is the main organ of the Department of Biological Sciences of the Russian Academy of Sciences. It publishes original materials on the results of basic studies in general biology (theoretical and evolutionary biology, cell biology, development biology, genetics, biochemistry, microbiology, botany, zoology, ecology, soil biology, and the physiology of plants, animals, and humans).

The journal is published in Russian and English. The English version Biology Bulletin is issued simultaneously with the Russian version. The published articles are included in the lists of the leading international reference editions and the Web of Science and Scopus information systems.

The journal publishes the papers of Russian and foreign authors, including materials obtained from projects of national and international scientific research programs. This scope underlies its demand and high rating among the biological journals of the Russian Academy of Sciences.

Editor-in-chief, Corresponding Member of the Russian Academy of Sciences, B.R. Striganova Translated by N. Smolina 